\title{
On the Dimers Stability of Allicin and Its Derivatives Interacting with AT, GC, and DNA Bridge: DFT Study
}

\author{
Mindaugas Macernis \\ Theoretical Physics Department, Faculty of Physics, Vilnius University, Sauletekio al. 3, B421, LT-10222 Vilnius, Lithuania \\ Correspondence should be addressed to Mindaugas Macernis; mindaugas.macernis@ff.vu.lt
}

Received 13 November 2016; Revised 15 February 2017; Accepted 26 February 2017; Published 19 March 2017

Academic Editor: Davut Avci

Copyright (C) 2017 Mindaugas Macernis. This is an open access article distributed under the Creative Commons Attribution License, which permits unrestricted use, distribution, and reproduction in any medium, provided the original work is properly cited.

\begin{abstract}
Allicin and its derivatives are physiologically active molecules with many potential health benefits. It is not clear if they have a direct effect on DNA or protein. In order to elucidate the allicin and its derivatives' effect on DNA base pairs, we investigated various complexes of base pair and its bridge with an allicin and its derivatives. The investigated allicin derivatives were (E)-Ajoene, (Z)-Ajoene, Amz121, and Bmz73 radicals. The DFT calculation results revealed that the investigated molecules would favor binding to bridge of the base pairs instead of directly affecting the base pairs. The Bmz73 radical could break DNA by change bonding in it because the Bmz73 radical significantly affected the $\mathrm{P}-\mathrm{O}$ bond of the bridge of base pair.
\end{abstract}

\section{Introduction}

Infections that develop into chronic conditions are a fastgrowing problem; especially it is important in the developed world $[1,2]$. In relation to emerging multiresistant bacteria, development of antimicrobials and new treatment strategies of infections should be expected to become a high-priority research area [2]. Indeed, garlic has been used for centuries because of its therapeutic and health-promoting properties $[3,4]$. Allicin is almost exclusively responsible for the antimicrobial activity of freshly crushed garlic [4]. Allicin is a physiologically active molecule with many potential health benefits [4] but there are many unanswered questions about its functions [1,5-13]. Allicin is active against a broader spectrum of microorganisms than most of the commonly used antibiotics. For example, allicin is active against both Gram positive (e.g., Bacillus and Streptococcus) and Gram negative bacteria (e.g., Salmonella typhimurium and Agrobacterium tumefaciens), whereas penicillin is practically not effective against the latter $[14,15]$. Allicin is also active against human pathogens that are resistant against certain antibiotics $[1,16]$. Beyond its well documented strong antibacterial properties allicin also shows toxic effects towards fungal cells and is able to inhibit spore germination and hyphal growth in vivo and in vitro $[1,17]$. Allicin showed promising activity against many plant-pathogenic fungal species, including pests, which are of economic importance also [4].

When allicin is inside the cell, the antibiotic efficiency depends upon reaching and reacting with its targets and on the importance of those targets to the cell [4]. Sulfonic acids have been studied in many chemical reactions [1820]. However, the transformation rate of allicin depends on the applied techniques of transformation, temperature, and solvents nature [21]. There are additional potent antithrombotic agent from garlic which are (E,Z)-Ajoene [22-24] which have neuroprotective effects also [23]. The Ajoene structures are formed from a chemical reaction involving two allicin molecules. On the other hand the allicin molecule is unstable structure which forms radicals over chemical reactions depending on the environment. Depending on homolytic cleavage or heterolytic cleavage of the S-S bonds in the allicin there are allicin derivative radicals after dissociation of the S-S bond [25]. The most stable radicals are labeled as Amz121 and Bmz73 [25] (Figure 2). Allicin radicals are good candidates for possible DNA damage also [25].

Does allicin have an effect on DNA, RNA, and/or protein synthesis (Figure 1) [4]? In 1988, Feldberg et al. investigated the effect of allicin on the synthesis of DNA, RNA, and proteins in Salmonella typhimurium [26]. Unfortunately, it remains unclear if the effect observed really showed a direct 


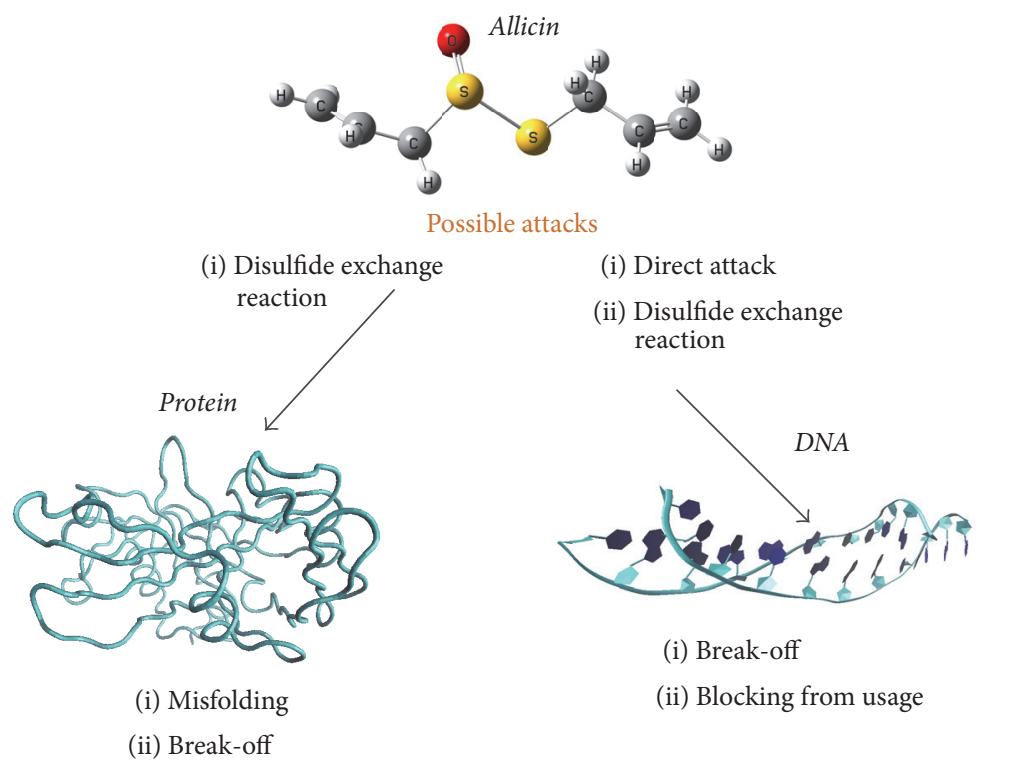

FIGURE 1: There are two possible allicin or its derivatives interactions: interacting with proteins or with DNA.

decrease in DNA, RNA, and protein synthesis (Figure 1) [4]. The possible allicin attacks on proteins are over disulfide exchange reaction what can lead to misfolding or break-off of the protein. Another possible attack is directly to DNA which can be two types directly affecting DNA or by structures after disulfide exchange reaction what can lead to break-off or blocking DNA from its usage.

According to Durlak et al. [9] CPMD simulations and DFT and MP2 methodology analysis there are about 20 conformers of allicin which have quite similar energies. In solvent any of allicin conformer can easy become from one to the other type conformer and the trans-allicin structure does not exist [9]. According to other DFT calculations together with experiment the alkali metal ions can strengthen the S1S1' bond in the allicin, while protonation or the loss of an electron weakens the S1S1' bond [27]. In the gas phase the dehydration reaction mechanism takes place easier for the allicin radical cation than for the protonated allicin [25]. According to other DFT analyses [28] it is more difficult in the intramolecular to transfer $\mathrm{H}$ atom during decomposition of allicin in ethanol.

The allicin derivatives which may be important for biological activity are allicin, Ajoene structures, or allicin radicals while possible effects are on protein or on DNA. This work was dedicated for computational analysis for the possible DNA damage models (Figure 2). In the present study, in order to elucidate the allicin and its derivatives effect on DNA base pairs, the stable structures and their electronic properties for the complexes of G-C, A-T base pairs, and base pairs bridge with an allicin, (E)-Ajoene, (Z)-Ajoene, and allicin radicals (Figure 3 ) by using the DFT calculations in vacuum were investigated. The results revealed that the allicin, Ajoene, and its allicin radical prefer to interact with the bridge of the base pairs. The calculation results showed that allicin and its derivative molecules would favor binding to bridge of the base pairs instead of directly affecting the C-G or A-T base pairs.

\section{Calculations and Investigated Structures}

2.1. Calculation Details. Despite several chemical reaction studies using HandHLYP/6-311++G(d,p) [29], (U)B3LYP/6$31+\mathrm{G}(\mathrm{d}, \mathrm{p})$ [25], or B3LYP/6-31+G (d,p) [27] levels of DFT theory there is lack of allicin or allicin radicals modeling. The allicin complexes are used for modeling of the complexes in $[9,30]$. In [9] for DFT calculations, B2PLYP/Def2-TZVPPD are used for single point calculations while optimization are performed using MP2/aug-cc-pVTZ. The vibrational analyses with M062X and PBE1PBE functional are not good enough according to experimental data [9]. The agreement with experimental data for on the dehydration reaction of the allicin calculations is achieved in [28] where (U)B3LYP/6$31+\mathrm{g}(\mathrm{d}, \mathrm{p})$ level calculation is used. The same calculation level (U)B3LYP/6-31+G(d,p) is used for theoretical studies on dissociation of the S-S bond in the allicin in [25] where results agree with the experimental data. The intermolecular interaction energy between allicin and solvent (pentane and ethanol) is calculated by DFT at the B3LYP/6-31+G(d,p) level in [27]. The B3LYP functional with 6-31G(d) [31], 6-311G(d,p) [3234], 6-311+G(2d,p) [32], 6-311++G(2d,p) [32], and cc-pVTZ [33] basis sets is good methods for modeling several small molecules as supermolecules in analyzing the proton transfer while the best results are by using cc-pVTZ basis set with B3LYP functional [32,33]. In these calculations all allicin type structures and DNA parts were computed using DFT theory with B3LYP/cc-pVTZ. The calculations were performed using the Gaussian 09 program package (Rev. D.01) [35].

According to [36] the optimization calculations should be performed by increasing basis set. The calculations were done in such way. Zero-point energy (ZPVE) corrections were not applied for the modeling of the complexes. BSSE-corrected energies were not taken for the analysis of final 45 groundstate complexes because the results should not change significantly as it is shown in [33]. All stationary points were 


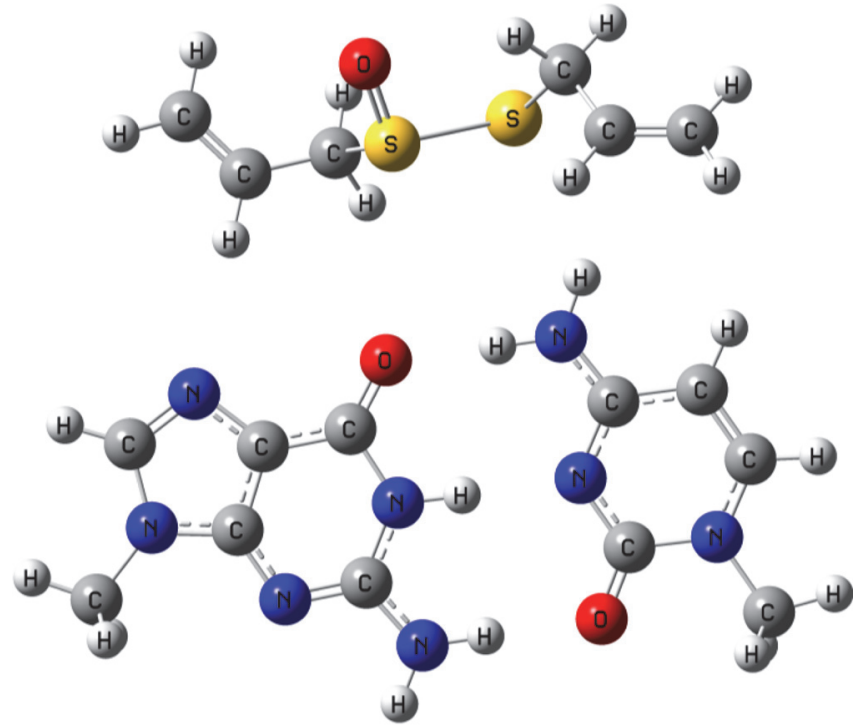

Position 1
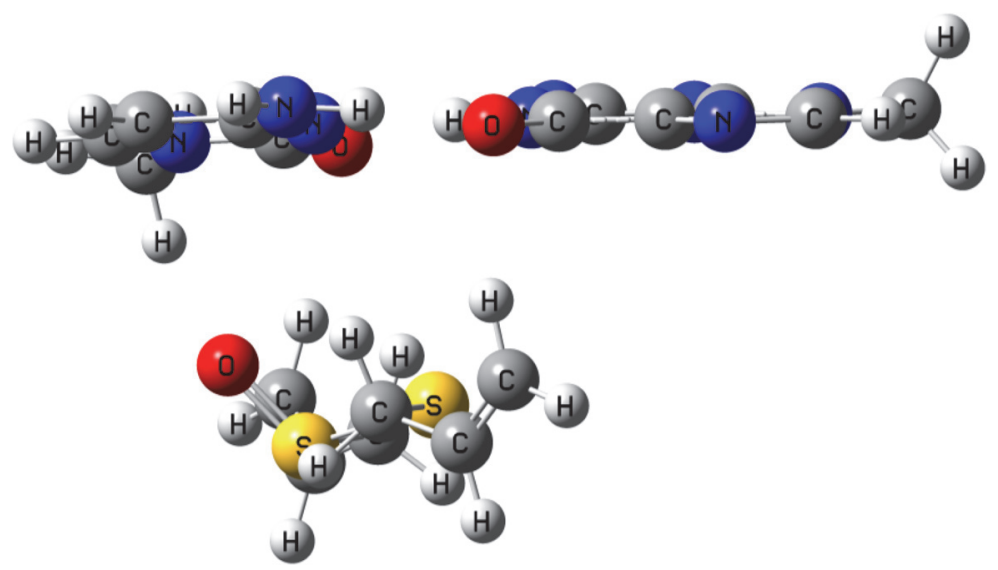

Position 2
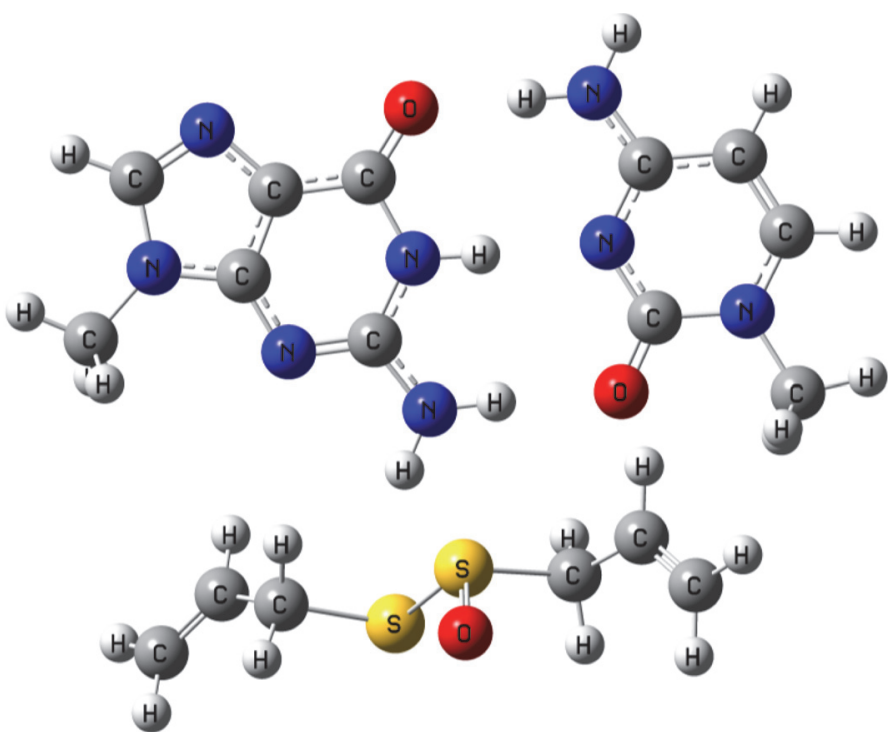

Position 3

(a)

Figure 2: Continued. 


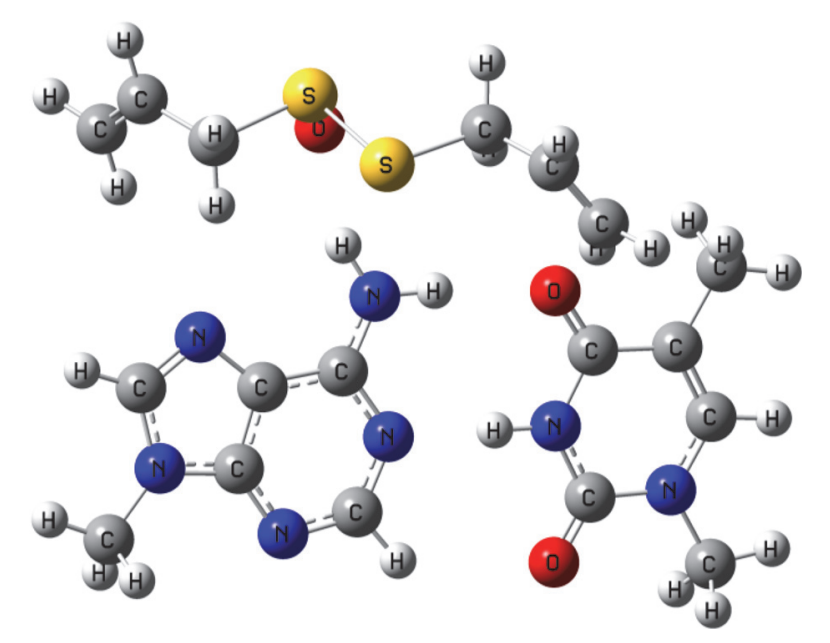

Position 1

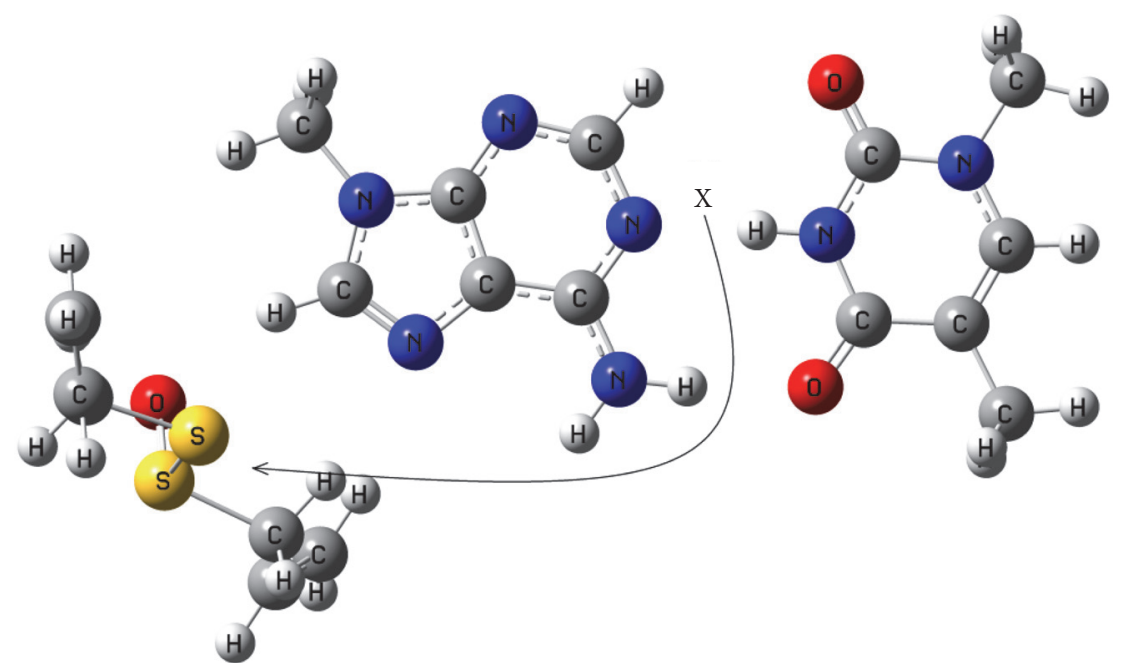

Position 2
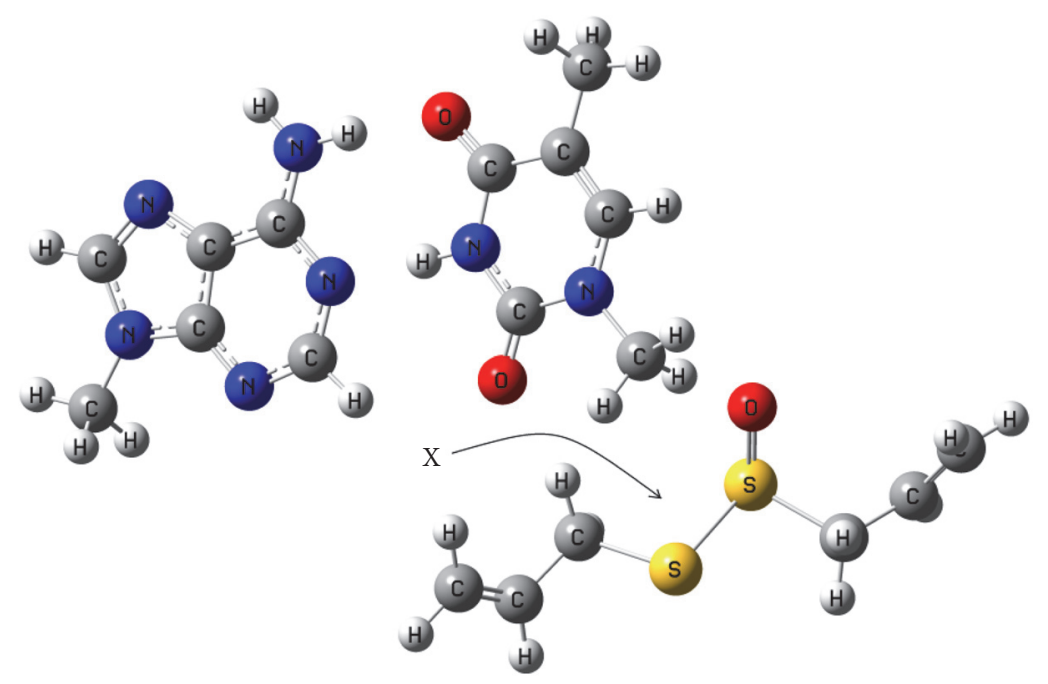

Position 3

(b)

Figure 2: Continued. 


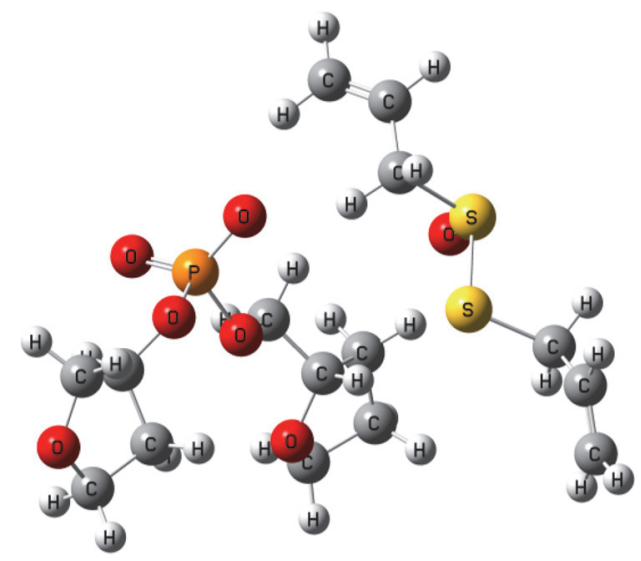

Position 1

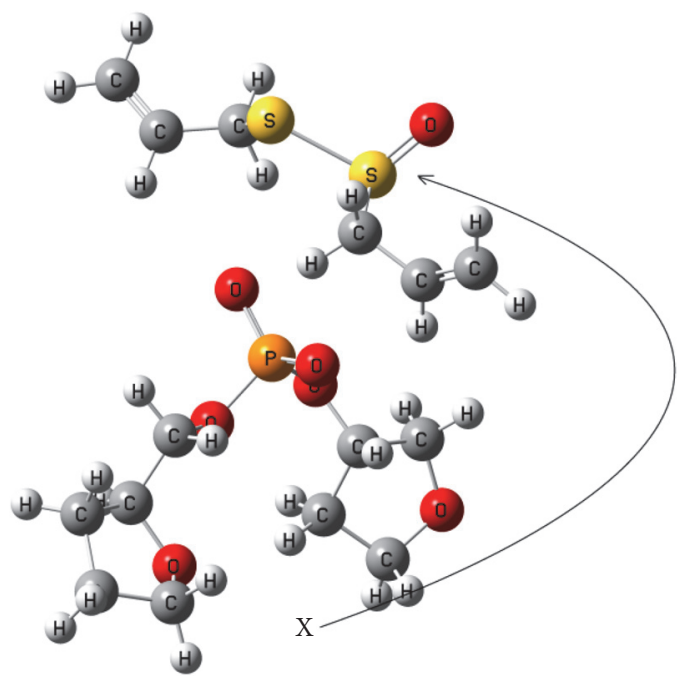

Position 2

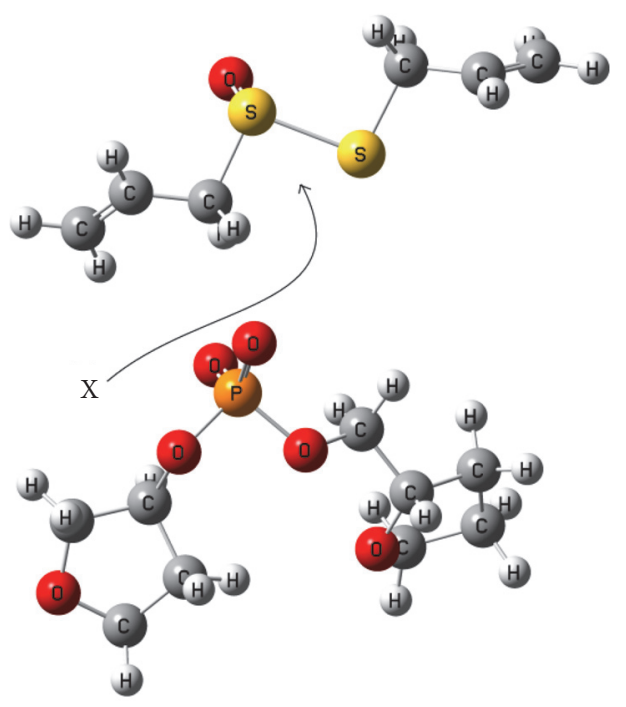

Position 3

(c)

FigURE 2: Investigated complex structures: allicin cases with G-C base pair (a), A-T base pair (b), and bridge of base pairs (c) after optimizations. X shows the initial position before optimization. Positions 1, 2, and 3 represent the pattern of artificial made initial model structures and its complexes. Similar complexes modeled with all interacting structures. 

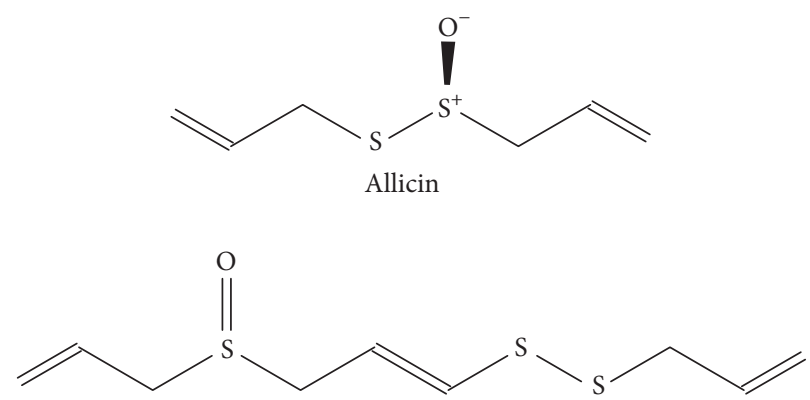

(E)-Ajoene

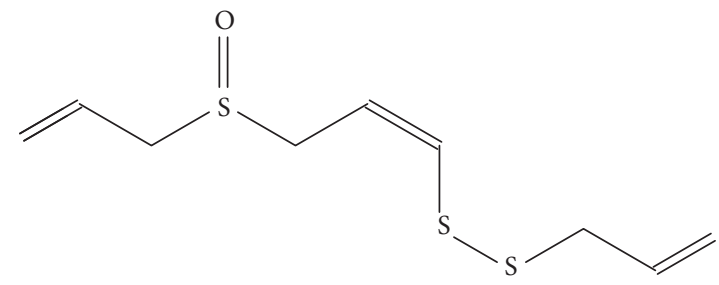

(Z)-Ajoene
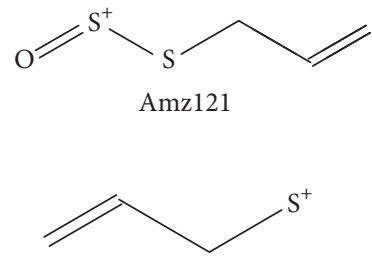

Bmz73

FIGURE 3: Interacting structures: allicin, (E)-Ajoene, (Z)-Ajoene, and allicin radicals labeled as Amz121 and Bmz73 in [25].

modeled in the gas phase (vacuum). Additionally, the allicin molecules were characterized by frequency analysis where frequency calculations having all real frequencies identify minimum structures.

There were analyses of chemical bonds of calculated complexes in the paper. The bond analysis was performed by analyzing Wiberg bond index. Primary focus was on the Wiberg bond index values between complex structures by looking for largest values. Also the distances between $\mathrm{S}$ atom of the interacting structure and nearest atom of the investigated structures were measured. Mulliken and NBO charges and HUMO-LUMO gap calculations for all the structures and complexes were performed.

Binding energies in the paper were calculated according to the following formula:

$$
\Delta E=E_{12}-\left(E_{1}+E_{2}\right)
$$

where $\Delta E$ is final binding energy, $E_{12}$ is energy of optimized interacting and investigated structures complex, $E_{1}$ is optimized interacting structure energy, and $E_{2}$ is optimized investigated structure energy.

2.2. Complexes of the Interacting Structures with the DNA Parts. For the modeling in this paper the primary idea was that the S-S must be active part for the possible interactions. Thus it was enough to have one stable conformer which had open form of the S-S bond. The interacting structures were allicin, (E)-Ajoene, (Z)-Ajoene, and allicin radicals labeled as Amz121 and Bmz73 similar to [24] (Figure 3). Frequency calculations showed the trans-allicin structure had five imaginary frequencies. The cis-allicin structures had not imaginary frequencies what meant they were in the minimum. Before modeling complexes all structures where optimized separately. The primary DNA structure was taken from PDB bank [37]. The DNA was divided into three major parts: G-C base pair, A-T base pair, and bridge of base pairs as it is shown in Figure 2. After optimization of DNA structural parts (G-C base pair, A-T base pair, and bridge of base pairs) the final structures were compared with crystallographic data [37]. The structures were quite similar and the difference was up to $5 \%$ for the bond lengths, angles, and dihedral angles. In order to find the most preferable interacting site of possible allicin derivatives around the DNA, artificial initial model structures were made by patterns as shown in Figure 2. The $\mathrm{S}$ atom or $\mathrm{S}$ atoms from $\mathrm{S}-\mathrm{S}$ bond were put as close to the DNA parts as possible. There were three major starting model positions for optimizations where the interacting structure was from different side of the investigated structure. In Figure 2 allicin cases with G-C base pair (Figure 2(a)), A-T 
base pair (Figure 2(b)), and bridge of base pairs (Figure 2(c)) are shown after the final optimizations. In Figure 2 the $\mathrm{X}$ sign represents the initial position before the optimization. Positions 1, 2, and 3 (Figure 2) were the patterns of artificial made initial model structures for the investigated complexes. The model structural parts were taken from separately optimized structures. Similar complexes were modeled and calculated with all interacting structures. The ground-state differences $\Delta E$ between same type complexes with different positions are shown in Table 1. There was no particular one position for interacting structure where the all complexes would be in the lowest ground state (Table 1).

\section{Results and Discussion}

3.1. Allicin Interaction with the DNA Structural Parts. Firstly, allicin molecule was put at three positions around G-C, A$\mathrm{T}$, and the bridge of the base pairs as shown in Figure 2. The results are presented in Table 1. The nearest position between allicin $\mathrm{S}$ and G-C part is $3.57 \AA$. The nearest distance to the A-T pair is $4.01 \AA$. The nearest $\mathrm{O}$ of the base pairs bridge from the allicin is $3.74 \AA$. In all cases the Wiberg bond index between dimer parts was almost zero: the largest value was 0.015 for $\mathrm{S}$ and $\mathrm{H}$ atoms in the case with G-C base pair (Table 1). The $S$ atoms had 0.48 and -0.13 Mulliken charges and 1.09 and $-0.04 \mathrm{NBO}$ charges in vacuum allicin. The charge values for the $S$ atoms were similar in complexes and they varied in 0.5 range. The HOMO-LUMO gaps in all cases were about $4 \mathrm{eV}$. The largest variations there were in the bridge of the base pairs case: the HOMO-LUMO gap was $4.79 \mathrm{eV}$ in position 2 and $3.66 \mathrm{eV}$ in position 1 . There was suggestion that the something would change if we put several allicin molecules. So two and three allicin complexes were used but there were no significant differences in results. There were several cases when one of the three types of allicin moved between A-T and G-C groups but this is unrealistic: in investigated model the A-T (or G-C) groups could freely move in the calculation space what is not true for the real DNA sequence. The binding energies between allicin and G$\mathrm{C}$ base pairs varied form $14.87 \mathrm{~kJ} / \mathrm{mol}$ to $31.75 \mathrm{~kJ} / \mathrm{mol}$. Similar results were between allicin and A-T base pairs where the binding energies varied from $21.48 \mathrm{~kJ} / \mathrm{mol}$ to $28.32 \mathrm{~kJ} / \mathrm{mol}$. The binding energies were almost twice stronger for the base pair bridge then for G-C or A-T base pairs, which varied from $42.8 \mathrm{~kJ} / \mathrm{mol}$ to $68.61 \mathrm{~kJ} / \mathrm{mol}$. Thus the results suggested that allicin molecules would favor binding to bridge of the base pairs and the calculated binding energies could be up to $70 \mathrm{~kJ} / \mathrm{mol}$. The calculation results showed that allicin molecule did not change significantly bonding between atoms of the DNA structural parts.

3.2. Ajoene Interaction with the DNA Structural Parts. With the same procedures as with allicin molecule, the calculations were performed for Ajoene molecules and those molecules are labeled as (E)-Ajoene and (Z)-Ajoene (Figure 3). The modeling was performed according to Figure 2 schema and results are presented in Table 1 where nearest positions between the $\mathrm{S}$ atom of Ajoene and $\mathrm{O}$ and $\mathrm{N}$ atoms of G-C, $\mathrm{A}-\mathrm{T}$, and the base pairs bridge are shown. In all cases the Wiberg bond index between dimer parts were almost zero: the largest value was 0.028 between $\mathrm{H}$ and $\mathrm{O}$ atoms in the case of (E)-Ajoene and bridge of the base pair complex (Table 1). The $S$ atoms of (E)-Ajoene had zero and -0.06 Mulliken charges and 0.14 and 0.08 NBO charges. The charge values for the $S$ atoms of (E)-Ajoene were similar in complexes and they varied in 0.05 range. The $S$ atoms of $(\mathrm{Z})$-Ajoene had -0.05 and -0.07 Mulliken charges and 0.09 and 0.08 NBO charges. The charge values for the $S$ atoms of (Z)-Ajoene were similar in complexes and they varied in 0.5 range. The HOMO-LUMO gaps for complexes varied from $3.37 \mathrm{eV}$ to $4.75 \mathrm{eV}$. The smallest HOMO-LUMO $3.37 \mathrm{eV}$ gap was for (E)-Ajoene with C-G base pair while the largest HOMOLUMO $4.75 \mathrm{eV}$ gap was for (E)-Ajoene with A-T base pair. The binding energies between Ajoene molecules and G-C or A-T base pairs varied from $8 \mathrm{~kJ} / \mathrm{mol}$ to $38 \mathrm{~kJ} / \mathrm{mol}$ where the largest bonding energy was between (Z)-Ajoene and G$\mathrm{C}$ base pair which was $37.68 \mathrm{~kJ} / \mathrm{mol}$. The binding energies were almost twice stronger for the base pair bridge and then for the G-C or A-T base pairs which were from $46.57 \mathrm{~kJ} / \mathrm{mol}$ to $85.82 \mathrm{~kJ} / \mathrm{mol}$. The results suggested that Ajoene molecules similar to allicin would favor binding to bridge of the base pairs and the binding was up to $85.82 \mathrm{~kJ} / \mathrm{mol}$. The calculation results showed that the Ajoene molecules did not change significantly bonding of the DNA structural parts.

\subsection{Allicin Radicals Interaction with the DNA Structural} Parts. Additional similar calculations were performed using allicin radicals: Amz121 and Bmz73 (Table 1). The Amz121 structure and G-C or A-T base pairs had binding energy from $251.51 \mathrm{~kJ} / \mathrm{mol}$ to $314.62 \mathrm{~kJ} / \mathrm{mol}$ which were very strong. The Wiberg bond indexes were from 0.476 to 0.638 . There were two types of bonding: between $\mathrm{S}$ and $\mathrm{O}$ (3 positions in G$\mathrm{C}$ base pair; all positions in A-T base pair cases); between $\mathrm{S}$ and $\mathrm{N}$ (1 and 2 positions in G-C base pair). The Amzl21 structure with bridge of the base pairs had binding energy twice larger: from $683.4 \mathrm{~kJ} / \mathrm{mol}$ to $686.12 \mathrm{~kJ} / \mathrm{mol}$. Also the Wiberg bond indexes were larger which were about 0.65 and they were between $\mathrm{S}$ and $\mathrm{O}$ atoms. The $\mathrm{S}$ atom of Amz121 had -0.06 Mulliken charge and 0.14 NBO charge. In all cases the $S$ atom donated electron because the charges became positive: $\mathrm{S}$ atoms of Amzl21 in complexes had 0.62-0.66 Mulliken charges and 1.34-1.47 NBO charges. The smallest HOMO-LUMO gaps from $2.96 \mathrm{eV}$ to $3.76 \mathrm{eV}$ were for complexes with Amz121 and G-C base pair structures while the largest HOMO-LUMO gaps from $5.9 \mathrm{eV}$ to $6.24 \mathrm{eV}$ were for complexes with Amz121 and bridge of the base pair structures.

The Bmz73 structure and G-C or A-T base pairs had binding energy from $375.12 \mathrm{~kJ} / \mathrm{mol}$ to $433.7 \mathrm{~kJ} / \mathrm{mol}$. The Wiberg bond indexes were from 0.77 to 0.91 . There were two types of bonding: between $\mathrm{S}$ and $\mathrm{O}$ ( 3 positions in G-C base pair; 1 position in A-T base pair cases); between $\mathrm{S}$ and $\mathrm{N}$ (1 and 2 positions in G-C base pair; 2 and 3 positions in A-T base pair). The Bmz73 structure with bridge of the base pairs had binding energy almost twice larger: from $674 \mathrm{~kJ} / \mathrm{mol}$ to $802 \mathrm{~kJ} / \mathrm{mol}$. The Wiberg bond indexes were about 0.8 and they were between $\mathrm{S}$ and $\mathrm{O}$ atoms. The $\mathrm{S}$ atom of $\mathrm{Bmz} 73$ had 0.32 


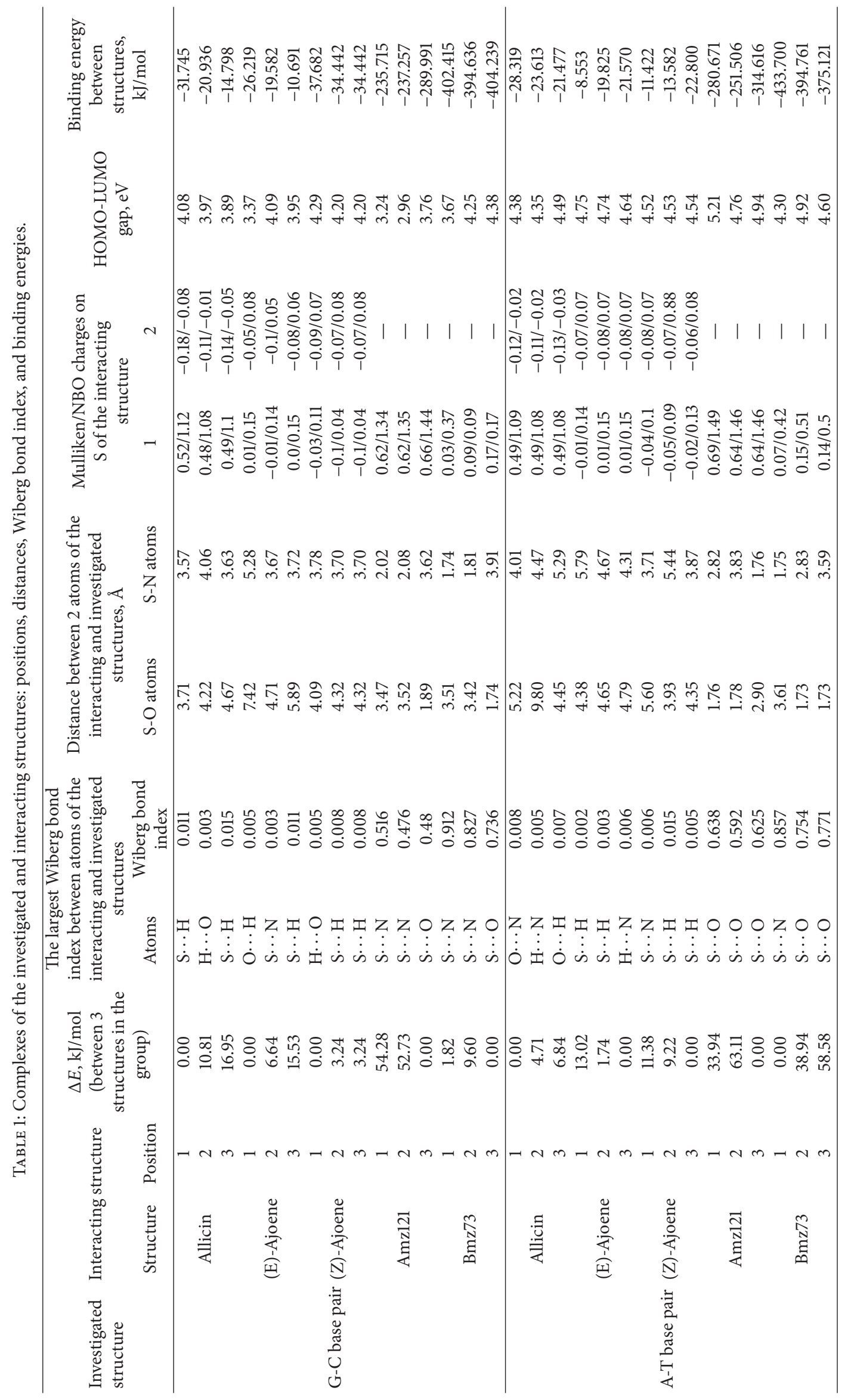




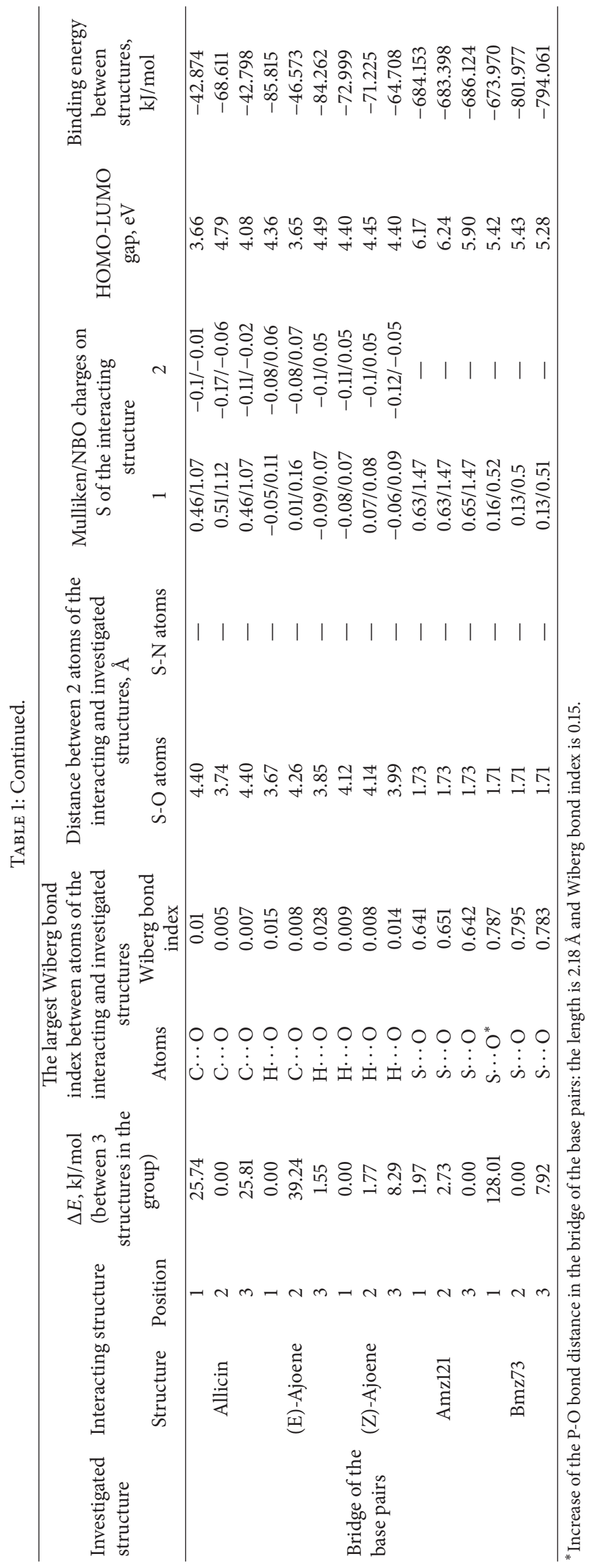


Mulliken charge and $0.56 \mathrm{NBO}$ charge. The NBO charges on the $S$ atom were quite similar for the A-T base pair complex and for the bridge of the base pair complex: $S$ atoms of Bmz73 had 0.07-0.16 Mulliken charges and 0.42-0.52 NBO charges. In $\mathrm{C}-\mathrm{G}$ base pair complex case the $\mathrm{S}$ atom the charges became less positive: $\mathrm{S}$ atoms of Bmz73 in C-G base pair complex had 0.03-0.17 Mulliken charges, $0.09-0.37$ NBO charges. The smallest HOMO-LUMO gaps from $3.67 \mathrm{eV}$ to $4.38 \mathrm{eV}$ were for complexes with Bmz73 and G-C base pair structures while the largest HOMO-LUMO gaps from $5.28 \mathrm{eV}$ to $5.43 \mathrm{eV}$ were for complexes with Bmz73 and bridge of the base pair structures.

Bmz73 radical significantly changes $\mathrm{P}-\mathrm{O}$ bond length of the bridge from $1.68 \AA$ to $2.18 \AA$ in 1 position complex. The P-O bond enthalpy was $389.84 \mathrm{~kJ} / \mathrm{mol}$ without Bmz73 radical. The P-O bond enthalpy became 9 times smaller $(42.52 \mathrm{~kJ} / \mathrm{mol})$ in complex of Bmz73 and bridge of the pair base. The P-O bond Wiberg bond index was 0.58 for the bridge of the base pair without Bmz73. The P-O bond Wiberg bond index became 0.15 in complex of the Bmz73 and the bridge of the base pair. In this case the $\mathrm{O}$ atom of the bridge of the base pair had new 0.79 Wiberg bond index with the $\mathrm{S}$ atom of the Bmz73 radical. Thus Bmz73 can break or significantly affect the P-O bonding in the bridge of DNA.

\section{Conclusions}

The DFT calculations with B3LYP/cc-pVTZ were performed between interacting structures and DNA parts (G-C and A$\mathrm{T}$ base pairs and the base pairs bridge) where interacting structures were allicin, Ajoene structures, and allicin radicals. The allicin analyses suggested the allicin structure was in minimum when it has cis-configuration. In all case of the allicin, Ajoene molecules with the DNA parts had almost zero Wiberg bond indexes. Allicin radicals had Wiberg bond indexes from 0.5 to 0.9 with the DNA structural parts. In Bmz73 radical case it significantly affected the $\mathrm{P}-\mathrm{O}$ bonding of the bridge of base pair. This means that the Bmz73 radical could break DNA by change bonding in it. All calculation results showed that allicin and its derivative molecules would favor binding to the bridge of the base pairs instead of directly affecting $\mathrm{C}-\mathrm{G}$ or A-T base pairs.

\section{Conflicts of Interest}

The author declares that there are no conflicts of interest regarding the publication of this article.

\section{Acknowledgments}

The public access supercomputer from the High Performance Computing Center (HPCC) of the Lithuanian National Center of Physical and Technology Sciences (NCPTS) at Vilnius University was used. Mindaugas Macernis acknowledge the prize for research of young scientists by the Lithuanian Academy of Science. This work is funded by the Research Council of Lithuania (LMT Grant no. MIP-080/2015).

\section{References}

[1] A. Marchese, R. Barbieri, A. Sanches-Silva et al., "Antifungal and antibacterial activities of allicin: a review," Trends in Food Science \& Technology, vol. 52, pp. 49-56, 2016.

[2] T. H. Jakobsen, M. Van Gennip, R. K. Phipps et al., "Ajoene, a sulfur-rich molecule from garlic, inhibits genes controlled by quorum sensing," Antimicrobial Agents and Chemotherapy, vol. 56, no. 5, pp. 2314-2325, 2012.

[3] J. H. Cardellina, "Review of garlic and other alliums. the lore and the science," Journal of Natural Products, vol. 76, no. 4, p. 813, 2013.

[4] J. Borlinghaus, F. Albrecht, M. C. H. Gruhlke, I. D. Nwachukwu, and A. J. Slusarenko, "Allicin: chemistry and biological properties," Molecules, vol. 19, no. 8, pp. 12591-12618, 2014.

[5] J. H. Cha, Y. J. Choi, S. H. Cha, C. H. Choi, and W. H. Cho, "Allicin inhibits cell growth and induces apoptosis in U87MG human glioblastoma cells through an ERK-dependent pathway," Oncology Reports, vol. 28, no. 1, pp. 41-48, 2012.

[6] C. Abbehausen, S. F. Sucena, M. Lancellotti et al., "Synthesis, spectroscopic characterization, DFT studies, and antibacterial and antitumor activities of a novel water soluble $\mathrm{Pd}(\mathrm{II})$ complex with L-alliin," Journal of Molecular Structure, vol. 1035, pp. 421426, 2013.

[7] W. Bat-Chen, T. Golan, I. Peri, Z. Ludmer, and B. Schwartz, "Allicin purified from fresh garlic cloves induces apoptosis in colon cancer cells via Nrf2," Nutrition and Cancer, vol. 62, no. 7, pp. 947-957, 2010.

[8] A. Rabinkov, T. Miron, L. Konstantinovski, M. Wilchek, D. Mirelman, and L. Weiner, "The mode of action of allicin: trapping of radicals and interaction with thiol containing proteins," Biochimica et Biophysica Acta, vol. 1379, no. 2, pp. 233244, 1998.

[9] P. Durlak, S. Berski, and Z. Latajka, "Theoretical studies on the molecular structure, conformational preferences, topological and vibrational analysis of allicin," Chemical Physics Letters, vol. 644, pp. 5-13, 2016.

[10] P. Elia, A. Azoulay, and Y. Zeiri, "On the efficiency of water soluble antioxidants," Ultrasonics Sonochemistry, vol. 19, no. 2, pp. 314-324, 2012.

[11] T. Miron, M. Wilchek, A. Sharp et al., "Allicin inhibits cell growth and induces apoptosis through the mitochondrial pathway in HL60 and U937 cells," Journal of Nutritional Biochemistry, vol. 19, no. 8, pp. 524-535, 2008.

[12] S. Oommen, R. J. Anto, G. Srinivas, and D. Karunagaran, "Allicin (from garlic) induces caspase-mediated apoptosis in cancer cells," European Journal of Pharmacology, vol. 485, no. 1-3, pp. 97-103, 2004.

[13] S.-Y. Park, S.-J. Cho, H.-C. Kwon, K.-R. Lee, D.-K. Rhee, and S. Pyo, "Caspase-independent cell death by allicin in human epithelial carcinoma cells: involvement of PKA," Cancer Letters, vol. 224, no. 1, pp. 123-132, 2005.

[14] C. J. Cavallito and J. H. Bailey, "Allicin, the antibacterial principle of Allium sativum. I. Isolation, physical properties and antibacterial action," Journal of the American Chemical Society, vol. 66, no. 11, pp. 1950-1951, 1944.

[15] A. S. Mozaffari Nejad, S. Shabani, M. Bayat, and S. E. Hosseini, "Antibacterial effect of garlic aqueous extract on Staphylococcus aureus in hamburger," Jundishapur Journal of Microbiology, vol. 7, no. 11, Article ID e13134, 2014.

[16] R. R. Cutler and P. Wilson, "Antibacterial activity of a new, stable, aqueous extract of allicin against methicillin-resistant 
Staphylococcus aureus," British Journal of Biomedical Science, vol. 61, no. 2, pp. 71-74, 2004.

[17] H. Curtis, U. Noll, J. Störmann, and A. J. Slusarenko, "Broadspectrum activity of the volatile phytoanticipin allicin in extracts of garlic (Allium sativum L.) against plant pathogenic bacteria, fungi and Oomycetes," Physiological and Molecular Plant Pathology, vol. 65, no. 2, pp. 79-89, 2004.

[18] D. R. Hogg, Chemistry of Sulphenic Acids and Esters, Sulfenic Acids and Derivatives, John Wiley \& Sons, Ltd, New York, NY, USA, 2010.

[19] M. C. Aversa, P. Bonaccorsi, D. Madec, G. Prestat, and G. Poli, "The fabulous destiny of sulfenic acids," in Innovative Catalysis in Organic Synthesis, pp. 47-76, Wiley-VCH, 2012.

[20] D. P. Ilic, V. D. Nikolic, L. B. Nikolic et al., "Allicin and related compounds: biosynthesis, synthesis and pharmacological activity," Facta Universitatis, Series Physics, Chemistry and Technology, vol. 9, pp. 9-20, 2011.

[21] D. Ilić, V. Nikolić, M. Stanković et al., "Transformation of synthetic allicin: the influence of ultrasound, microwaves, different solvents and temperatures, and the products isolation," The Scientific World Journal, vol. 2012, Article ID 561823, 7 pages, 2012.

[22] M. Li, J.-R. Ciu, Y. Ye et al., "Antitumor activity of Z-ajoene, a natural compound purified from garlic: antimitotic and microtubule-interaction properties," Carcinogenesis, vol. 23, no. 4, pp. 573-579, 2002.

[23] D. Y. Yoo, W. Kim, S. M. Nam et al., "Neuroprotective effects of Z-ajoene, an organosulfur compound derived from oilmacerated garlic, in the gerbil hippocampal CA1 region after transient forebrain ischemia," Food and Chemical Toxicology, vol. 72, pp. 1-7, 2014.

[24] E. Block and S. Ahmad, "(E,Z)-Ajoene: a potent antithrombotic agent from garlic," Journal of the American Chemical Society, vol. 106, pp. 8295-8296, 1984.

[25] X. Zhang, "Mass spectrometric and theoretical studies on dissociation of the SS bond in the allicin: homolytic cleavage vs heterolytic cleavage," Journal of Molecular Structure, vol. 1020, pp. 63-69, 2012.

[26] R. S. Feldberg, S. C. Chang, A. N. Kotik et al., "In vitro mechanism of inhibition of bacterial cell growth by allicin," Antimicrobial Agents and Chemotherapy, vol. 32, no. 12, pp. 1763-1768, 1988.

[27] H. Zhou, W.-Q. Li, R.-A. Yan, X.-S. Huang, and S.-Y. Ou, "Decomposition kinetics of allicin in pentane and ethanol," Modern Food Science and Technology, vol. 29, no. 11, pp. 25912594, 2013.

[28] X. Zhang and C. Xiong, "Theoretical studies on the dehydration reaction of the allicin radical cation in the gas phase," Computational and Theoretical Chemistry, vol. 972, no. 1-3, pp. 75-80, 2011.

[29] A. Galano and M. Francisco-Marquez, "Peroxyl-radicalscavenging activity of garlic: 2-propenesulfenic acid versus allicin," Journal of Physical Chemistry B, vol. 113, no. 49, pp. 16077-16081, 2009.

[30] W.-Q. Li, H. Zhou, X.-P. Hu et al., "Effects of allicin and organic solvents on the alliinase activity and composition of garlic oil," Modern Food Science and Technology, vol. 30, no. 11, pp. 79-83, 2014.

[31] B. P. Kietis, M. MacErnis, J. Sulskus, and L. Valkunas, "Estimation of the permanent dipole moment of bacteriorhodopsin," Lithuanian Journal of Physics, vol. 50, no. 4, pp. 451-462, 2010.
[32] M. Macernis, B. P. Kietis, J. Sulskus, S. H. Lin, M. Hayashi, and L. Valkunas, "Triggering the proton transfer by H-bond network," Chemical Physics Letters, vol. 466, no. 4-6, pp. 223-226, 2008.

[33] S. Toliautas, M. Macernis, J. Sulskus, and L. Valkunas, "Solvent effect on the photo-induced proton transfer in 2-(N-methyl- $\alpha$ iminoethyl)-phenol," Chemical Physics Letters, vol. 591, pp. 5257, 2014.

[34] M. Macernis, D. Galzerano, J. Sulskus et al., "Resonance Raman spectra of carotenoid molecules: influence of methyl substitutions," The Journal of Physical Chemistry A, vol. 119, no. 1, pp. 56-66, 2015.

[35] M. J. Frisch, G. W. Trucks, H. B. Schlegel et al., Gaussian 09, Gaussian, Inc., Wallingford, Conn, USA, 2009.

[36] C. J. Cramer, Essentials of Computational Chemistry: Theories and Models, John Wiley \& Sons, West Sussex, UK, 2nd edition, 2004.

[37] M. Sokolowska, M. Kaus-Drobek, H. Czapinska et al., "Monomeric restriction endonuclease BCNI in the apo form and in an asymmetric complex with target DNA," Journal of Molecular Biology, vol. 369, no. 3, pp. 722-734, 2007. 

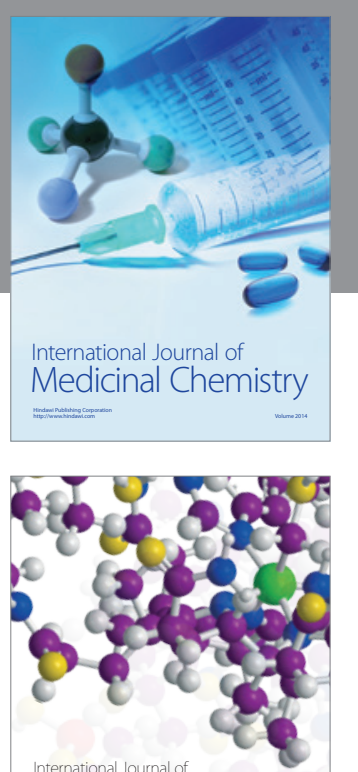

Carbohydrate Chemistry

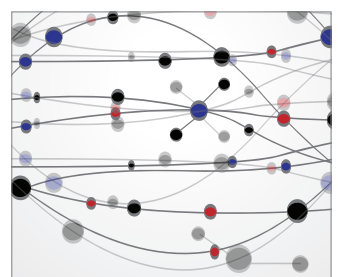

The Scientific World Journal
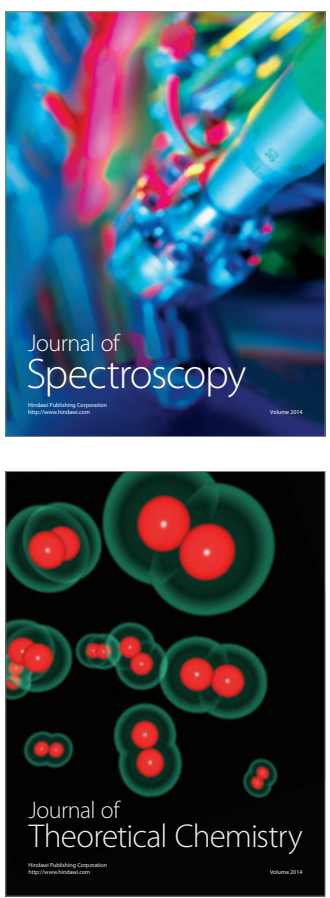
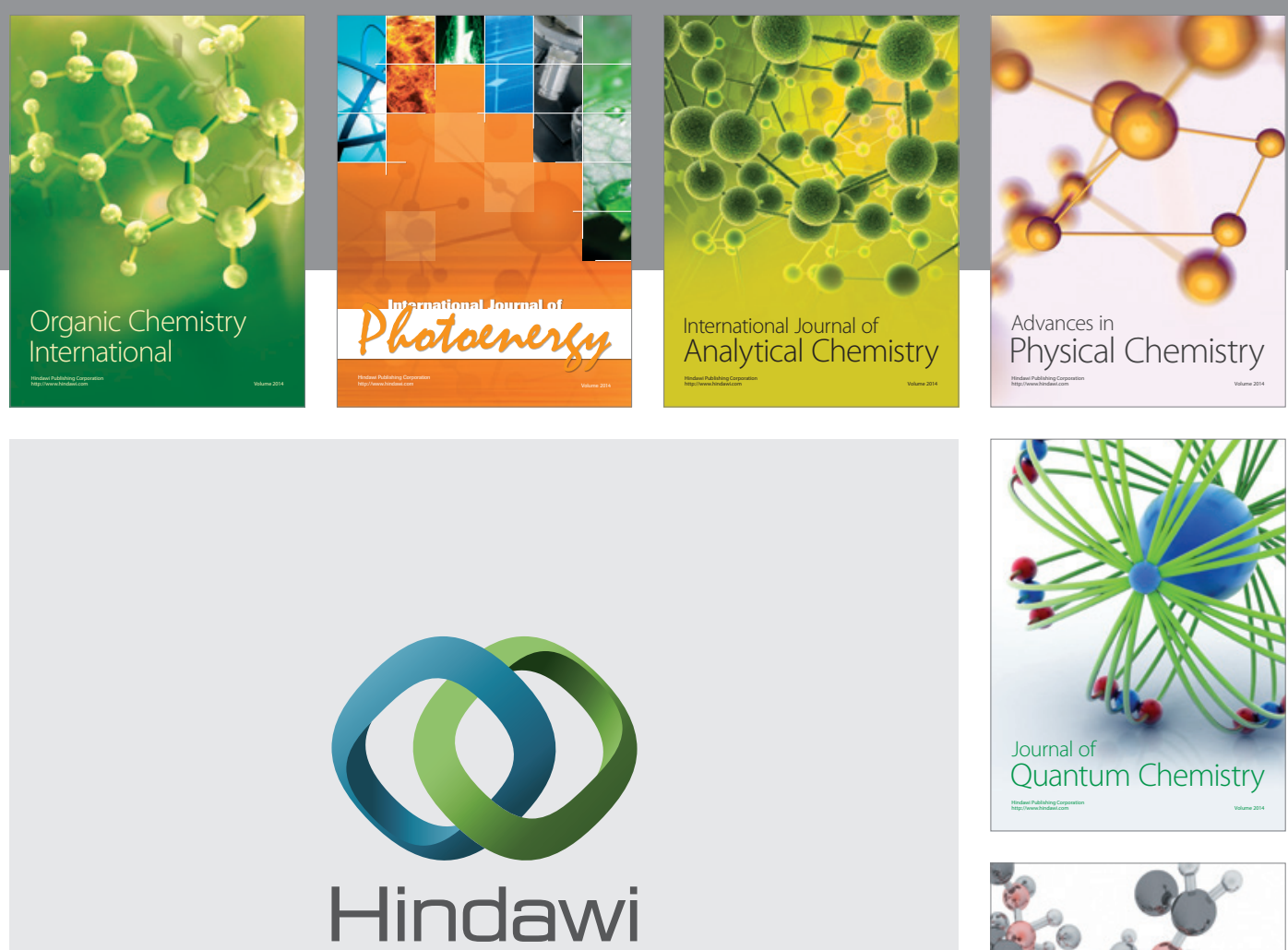

Submit your manuscripts at

https://www.hindawi.com

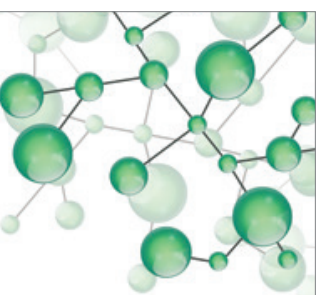

International Journal of

Inorganic Chemistry
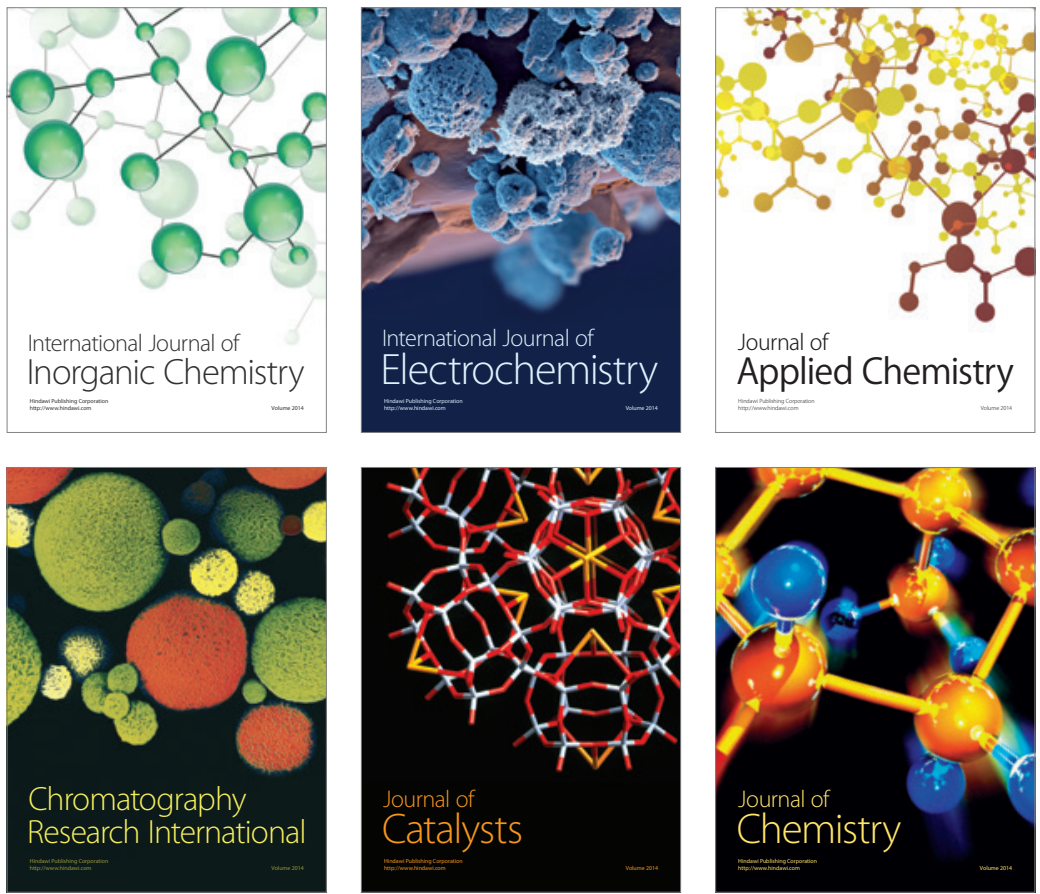

Journal of

Applied Chemistry
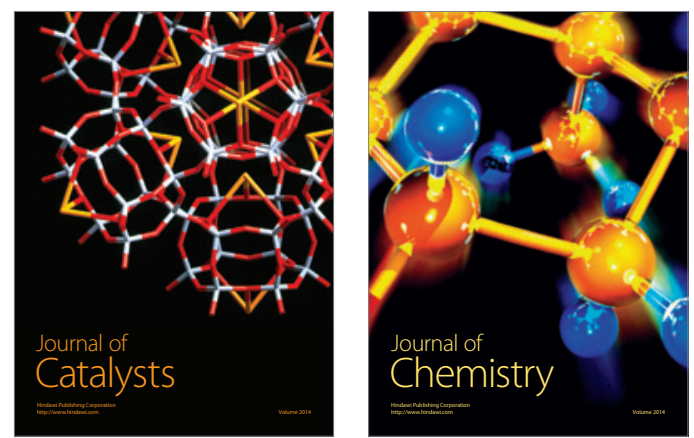
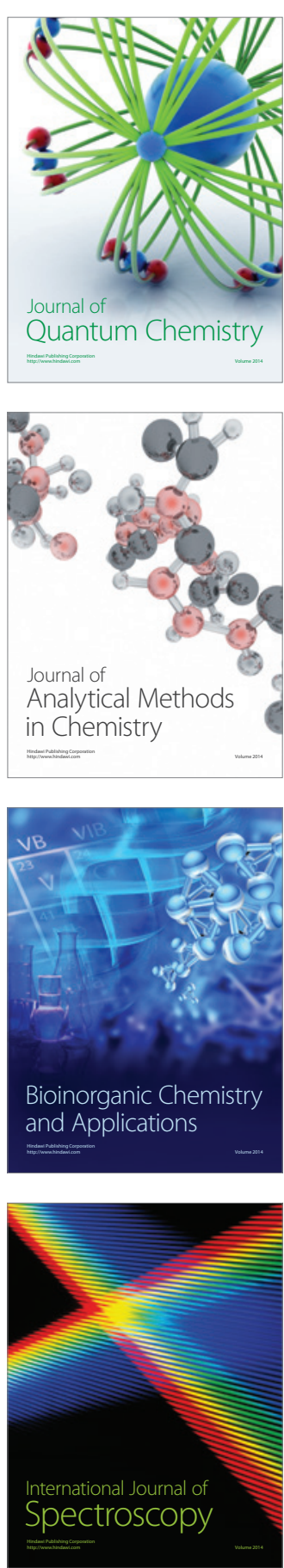